Research Paper

\title{
TNFAIP3 gene rs10499194, rs13207033 polymorphisms decrease the risk of rheumatoid arthritis
}

\author{
Ming-Jie Wang ${ }^{1, *}$, Hao-Yu Yang ${ }^{1, *}$, Hui Zhang ${ }^{1}$, Xindie Zhou ${ }^{1}$, Rui-Ping Liu ${ }^{1}$, \\ Yuan-Yuan $\mathbf{M i}^{2}$ \\ ${ }^{1}$ Department of Orthopedics, Affiliated Hospital of Nanjing Medical University, Changzhou Second People's Hospital, \\ Changzhou, China \\ ${ }^{2}$ Department of Urology, The Third Affiliated Hospital of Nantong University, Wuxi, PR China \\ *These authors have contributed equally to this work \\ Correspondence to: Rui-Ping Liv, email: liuruiping216@sina.com \\ Yuan-yuan Mi, email: myywxsy2016@sina.com \\ Keywords: TNFAIP3, rheumatoid arthritis, meta-analysis, single nucleotide polymorphism \\ Received: August 08, $2016 \quad$ Accepted: September 23, $2016 \quad$ Published: October 13, 2016
}

\section{ABSTRACT}

Accumulating evidences suggested that tumor necrosis factor alpha inducible protein 3 (TNFAIP3) gene rs10499194, rs13207033 polymorphisms may be associated with the risk of rheumatoid arthritis (RA). However, these studies yielded contradictory findings. To clarify convincing associations, we conducted a comprehensive metaanalysis by searching in PubMed, Embase, and the China Knowledge Resource Integrated Database. Pooled odds ratios (ORs) and $95 \%$ confidence intervals (CIs) were calculated by using fixed-effect or random-effect models. A total of 13 case-control studies for rs10499194 polymorphism and 6 studies for rs 13207033 polymorphism were included. Our data indicated that TNFAIP3 gene rs10499194, rs13207033 polymorphisms were associated with the decreased risk of RA. Stratification analyses of ethnicity indicated rs10499194, rs13207033 polymorphisms decreased the risk of RA among Caucasian populations, but not among Asian populations. In conclusion, this meta-analysis indicates that TNFAIP3 gene rs10499194, rs13207033 polymorphisms decrease the risk of RA, especially among Caucasian populations.

\section{INTRODUCTION}

Rheumatoid arthritis (RA) is an autoimmune inflammatory disease, which is characterized by chronic destructive inflammation in synovial joints. To date, the etiology of RA is poorly understood, but it is believed that complex genetic and environmental factors play important roles in the pathogenesis of RA [1]. Previous studies have suggested that genetic factors may be account for approximately $50-65 \%$ of the risk of RA [2]. Human leukocyte antigen (HLA) alleles are well recognized to be implicated in the pathogenesis of RA [3]. However, family studies indicated that HLA alleles contribute to about $30 \%$ of genetic susceptibility and that non-HLA loci are also related to $\mathrm{RA}[2,4]$.

Tumor necrosis factor alpha inducible protein 3 (TNFAIP3), a deubiquitinating protein, is reported to play a pivotal role in $\mathrm{T}$ cell activation and inflammatory signaling [5]. It can deregulate NF- $\kappa \mathrm{B}-$ dependent gene expression via deubiquitinating specific NF- $\kappa \mathrm{B}$ signaling molecules [6].
Genome-wide association studies (GWASs) have identified TNFAIP3 gene as a common genetic risk factor for RA [7, 8]. A host of studies [7, 9-21] investigated the associations between TNFAIP3 gene rs10499194, rs13207033 polymorphisms and RA susceptibility, but with conflicting findings. However, these studies were conflicting and inconclusive due to clinical heterogeneity, different ethnic populations, and small sample sizes. In order to precisely elucidate the genetic roles for TNFAIP3 gene polymorphisms (rs10499194, rs13207033) in the development of RA, we performed a comprehensive meta-analysis of identified studies to clarify the possible association between TNFAIP3 gene rs10499194, rs13207033 polymorphisms and RA risk.

\section{RESULTS}

Characteristics of the included studies

We yielded a total of 251 citations after initial search. 77 citations were removed because of duplicates, 
and 141 citations were excluded after screening the titles and abstracts. 33 citations were selected for further full text review. 19 citations were excluded due to the following reasons: 9 investigated other polymorphisms; 4 citations did not provide detailed genotyping data; 2 were about juvenile idiopathic arthritis; 3 were reviews; and 1 was not case-control study. We finally identified 14 eligible citations [7,9-21] including 17 studies $(23,918$ cases and 33,486 controls) in this metaanalysis. Selection for eligible studies included in this meta-analysis was presented in Figure 1. 6 studies with 11,166 cases and 11,231 controls examined rs13207033 polymorphism; 13 studies including 15,341 cases and 24,535 controls investigated rs 10499194 polymorphism. The characteristics of included studies are summarized in Table 1. The Newcastle-Ottawa Scale (NOS) scores of all included studies ranged from 5 to 7 stars, suggesting that these studies were of high methodological quality.

\section{Meta-analysis of TNFAIP3 gene rs10499194, rs13207033 polymorphisms}

In the overall analysis, we detected significant association (Table 2) between TNFAIP3 gene rs10499194, rs13207033 polymorphisms with decreased RA risk (rs10499194, TT vs. CT+CC: OR, 0.80; 95\%
CI, 0.74-0.88, $P<0.001$, Figure 2; rs13207033, GA vs. GG: OR, 0.88; 95\% CI, 0.79-0.99, $P=0.034$, Figure 3). Stratification analyses were conducted according to ethnicity (Table 3). Our data indicated that rs10499194 polymorphism was also significantly associated with a decreased risk of RA among Caucasian populations (TT vs. CT+CC: OR, 0.79; 95\% CI, $0.72-0.86, P<0.001$, Figure 4$)$, but not among Asian and African-American populations. We also found rs13207033 polymorphism was weakly associated with a decreased risk of RA among Caucasian populations (GA vs. GG: OR, 0.88; 95\% CI, 0.79-1.00, $P=0.044$ ). All included studies conform to Hardy-Weinberg equilibrium (HWE), indicating control subjects were representative of the general population.

We assessed sensitivity by omitting each study once at a time in every genetic model for rs10499194 and rs13207033 polymorphisms. The pooled ORs for the effects of these two single nucleotide polymorphisms (SNPs) (rs10499194, TT vs. CT+CC: Figure 5) on the risk for RA risk indicated that our data were stable and trustworthy. Both Egger's and Begg's tests (rs10499194: TT vs. CT $+\mathrm{CC}$, Figure 6) were used to evaluated the publication bias of this meta-analysis. Our data revealed that there was no obvious publication bias for rs 10499194 and rs13207033 polymorphisms (data not shown).

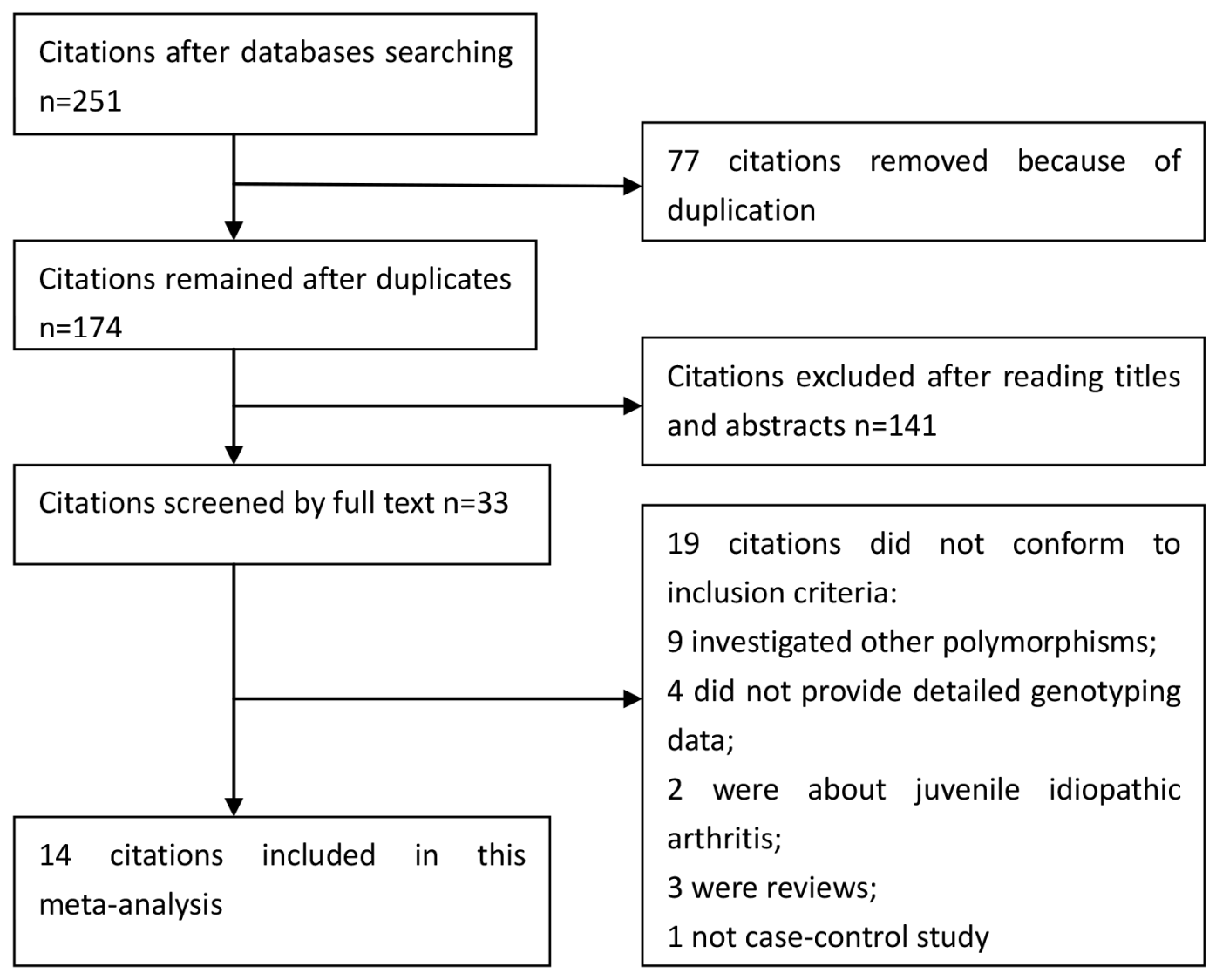

Figure 1: Selection for eligible publications included in this meta-analysis. 
Table 1: Characteristics of included studies

\begin{tabular}{|c|c|c|c|c|c|c|c|c|c|c|}
\hline \multirow{2}{*}{$\begin{array}{l}\text { Author and year } \\
\text { rs10499194 }\end{array}$} & \multirow[t]{2}{*}{ Country } & \multirow[t]{2}{*}{ Ethnicity } & \multicolumn{3}{|c|}{ Case } & \multicolumn{3}{|c|}{ Control } & \multirow[t]{2}{*}{ HWE } & \multirow[t]{2}{*}{ NOS } \\
\hline & & & $\mathrm{CC}$ & $\mathrm{CT}$ & $\mathrm{TT}$ & $\mathrm{CC}$ & $\mathrm{CT}$ & TT & & \\
\hline Hegab_2016 & Egypt & Caucasian & 319 & 71 & 3 & 344 & 52 & 2 & 0.982 & 6 \\
\hline Zhang_2014 & China & Asian & 1156 & 12 & 4 & 1215 & 63 & 2 & 0.218 & 6 \\
\hline Hughes_2010 & USA & $\begin{array}{l}\text { African- } \\
\text { American }\end{array}$ & 374 & 164 & 18 & 558 & 213 & 20 & 0.951 & 7 \\
\hline Shimane_2010 & Japan & Asian & 2944 & 450 & 17 & 2049 & 243 & 7 & 0.943 & 6 \\
\hline Han_2009 & Korea & Asian & 1199 & 113 & 2 & 936 & 66 & 1 & 0.883 & 5 \\
\hline Coenen_2009 & Dutch & Caucasian & 790 & 499 & 79 & 972 & 614 & 97 & 0.998 & 7 \\
\hline Stark_2009 & Slovakia & Caucasian & 281 & 200 & 37 & 149 & 116 & 37 & 0.058 & 6 \\
\hline Perdigones_2009 & Spain & Caucasian & 305 & 275 & 46 & 306 & 287 & 70 & 0.824 & 6 \\
\hline Raychaudhuri_2008 & Mixed & Caucasian & 1353 & 1522 & 428 & 4636 & 5929 & 1895 & 0.993 & 7 \\
\hline Plenge_2007 & USA & Caucasian & 229 & 145 & 23 & 195 & 167 & 36 & 0.977 & 6 \\
\hline Plenge_2007 & Sweden & Caucasian & 560 & 280 & 35 & 519 & 276 & 37 & 0.968 & 6 \\
\hline Plenge_2007 & North America & Caucasian & 317 & 190 & 28 & 496 & 426 & 91 & 0.973 & 6 \\
\hline Plenge_2007 & North America & Caucasian & 491 & 327 & 55 & 673 & 604 & 136 & 0.977 & 6 \\
\hline rs13207033 & & & $\overline{\mathrm{GG}}$ & GA & AA & GG & GA & $\mathrm{AA}$ & & \\
\hline Zhang_2014 & China & Asian & 1040 & 232 & 8 & 1048 & 216 & 16 & 0.203 & 7 \\
\hline Han_2009 & Korea & Asian & 987 & 295 & 27 & 773 & 208 & 19 & 0.257 & 5 \\
\hline Maxwell_2012 & UK & Caucasian & 149 & 106 & 13 & 129 & 116 & 16 & 0.129 & 6 \\
\hline Orozco_2009 & UK & Caucasian & 2067 & 1403 & 224 & 1563 & 1237 & 229 & 0.464 & 7 \\
\hline $\begin{array}{l}\text { Dieguez- } \\
\text { Gonzalez_2009 }\end{array}$ & Spain & Caucasian & 825 & 684 & 142 & 800 & 676 & 143 & 0.991 & 6 \\
\hline Plant_2010 & Mixed & Caucasian & 1614 & 1148 & 202 & 2214 & 1555 & 273 & 0.999 & 6 \\
\hline
\end{tabular}

HWE, Hardy-Weinberg equilibrium; NOS, Newcastle-Ottawa Scale

\section{DISCUSSION}

In this current meta-analysis, we found that TNFAIP3 gene rs10499194, rs13207033 polymorphisms were associated with the decreased risk of RA. Stratification analyses of ethnicity indicated that rs10499194 and rs13207033 polymorphisms decreased the risk of RA among Caucasians, but not among Asians.

Studies have demonstrated that NF- $\kappa \mathrm{B}$-dependent gene expression is significantly associated with the development of RA [21]. TNFAIP3 is an inhibitor of the $\mathrm{NF}-\kappa \mathrm{B}$ signaling pathway and it is indispensable in the development of RA [22]. Defects in TNFAIP3 expression are associated with development of RA [23]. Matmati et al. indicated that TNFAIP3 deficiency in myeloid cells triggers erosive polyarthritis resembling RA [24]. They revealed a pivotal and cell-specific function for TNFAIP3 in the pathogenesis of RA [24]. Recently, a number of [7,
9-21] studies explored the associations between TNFAIP3 gene polymorphisms (rs10499194, rs13207033) and RA risk. However, these studies obtained inconsistent results. The limitations of these studies including clinical heterogeneity, different ethnic populations, inadequate statistical power, and small sample sizes may contribute to the disaccord. Therefore, to obtain reliable conclusions, it is indispensable to conduct a comprehensive meta-analysis to demonstrate the associations between TNFAIP3 gene rs10499194, rs13207033 polymorphisms and RA susceptibility. Our data indicated that TNFAIP3 gene rs10499194 and rs13207033 polymorphisms decreased the risk of RA.

Previously, Lee et al. also performed a metaanalysis to investigate TNFAIP3 gene rs10499194 polymorphism with RA susceptibility [25]. They indicated that rs10499194 polymorphism was not associated with RA susceptibility [25]. Stratification 
Table 2: Meta-analysis of association between TNFAIP3 rs10499194, rs13207033 polymorphisms and RA risk

\begin{tabular}{llcccc}
\hline Comparison & OR(95\%CI) & $\boldsymbol{P}$-value & $\boldsymbol{P}$ for heterogeneity & $\mathbf{I}^{\mathbf{2}} \mathbf{( \% )}$ & Model \\
\hline rs10499194 & & & & & \\
T vs. C & $0.91(0.81,1.02)$ & 0.097 & $<0.001$ & 85.0 & Random \\
CT+TT vs. CC & $0.90(0.78,1.03)$ & 0.131 & $<0.001$ & 84.9 & Random \\
TT vs. CT+CC & $\mathbf{0 . 8 0 ( 0 . 7 4 , 0 . 8 8 )}$ & $<0.001$ & 0.115 & 33.4 & Fixed \\
CT vs. CC & $0.92(0.80,1.06)$ & 0.239 & $<0.001$ & 82.7 & Random \\
TT vs. CC & $\mathbf{0 . 7 5 ( 0 . 6 2 , 0 . 9 0 )}$ & 0.002 & 0.026 & 48.4 & Random \\
\hline rs13207033 & & & & & \\
A vs. G & $0.96(0.89,1.04)$ & 0.349 & 0.023 & 61.8 & Random \\
GA+AA vs. GG & $0.96(0.87,1.06)$ & 0.446 & 0.025 & 61.1 & Random \\
AA vs. GA+GG & $0.90(0.81,1.01)$ & 0.080 & 0.305 & 16.9 & Fixed \\
GA vs. GG & $\mathbf{0 . 8 8}(\mathbf{0 . 7 9 , 0 . 9 9 )}$ & 0.034 & 0.146 & 39.0 & Fixed \\
AA vs. GG & $0.97(0.89,1.07)$ & 0.556 & 0.062 & 52.4 & Random \\
\hline
\end{tabular}

*Bold values are statistically significant $(P<0.05)$.

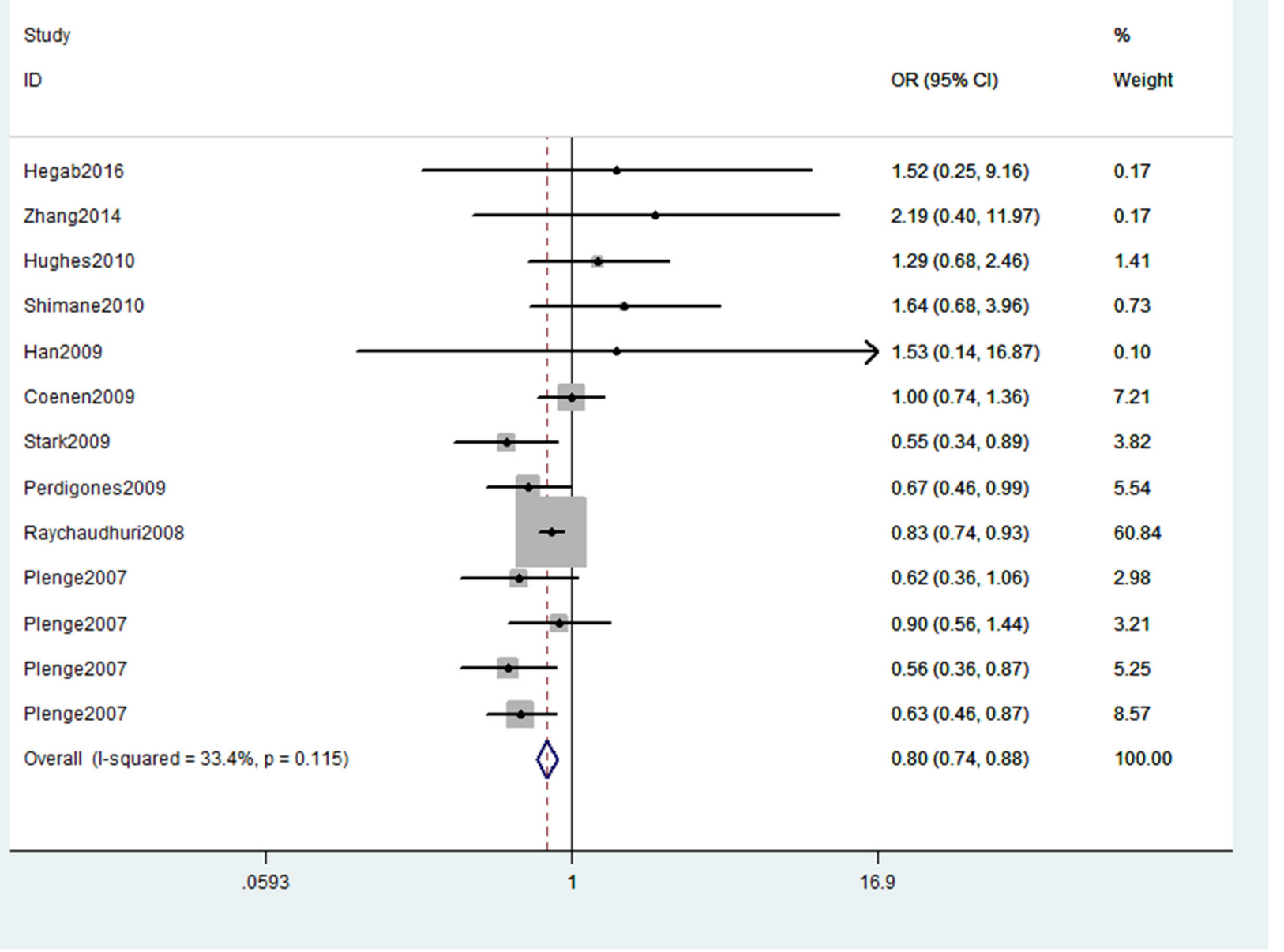

Figure 2: Forest plot shows odds ratio for the associations between rs10499194 polymorphism and RA risk (TT vs. CT+CC). 
analyses of ethnicity in their meta-analysis [25] suggested that rs10499194 polymorphism was weakly associated with an increased risk of RA among Asian populations, while no association was observed among Caucasian populations. However, our meta-analysis found that rs 10499194 polymorphism was significantly associated with a decreased risk of RA among Caucasian populations, but not among Asian populations, indicating that diversity inheritance of different ethnicities. The reasons why the decreased risk of RA among Asians is not obvious are still unclear. The clinical heterogeneity, different ethnicities and small sample sizes may explain it. We think previous meta-analysis [25] conducted by Lee et al. had several limitations. First, Lee et al. did not include two studies $[7,16]$ which actually conformed to the inclusion criteria. Second, they identified a Spanish study [10] by Dieguez-Gonzalez et al., but we did not find the genotype numbers of rs10499194 polymorphism. Three, previous research indicated that searching one or two databases was insufficient for meta-analysis of casecontrol studies [26]. Lee et al. conducted a literature search only in the database of MEDLINE, but omitting Embase and other databases. Consequently, the reliability of their conclusions should be interpreted with caution.
Due to these above limitations of previous meta-analysis, we re-conducted this meta-analysis. We believe our metaanalysis has some strength over previous meta-analysis for the following reasons. One, we identified 13 studies $[7,9,11-13,16,18-21]$, including 15,341 cases and 24,535 controls with regard to rs 10499194 polymorphism and the sample size of this meta-analysis was large enough. Two, sensitivity analysis indicated that our data about rs 10499194 polymorphism were trustworthy and robust. Three, the power analysis indicated that our study had a power of $99.9 \%$ to detect the effect of rs 10499194 polymorphism on RA susceptibility, assuming an OR of 0.80 .

Regarding TNFAIP3 gene rs13207033 polymorphism, six studies explored the association between this SNP and RA risk. A study from UK [15] found rs13207033 polymorphism was significantly associated with a decreased risk of RA, but the remaining five studies $[10,11,14,17,21]$ did not replicate the association. Therefore, we conducted the meta-analysis to demonstrate this SNP with RA risk. To our knowledge, this is the first meta-analysis to address the association between this SNP and RA risk. A weak association was obtained about rs13207033 polymorphism in our study.

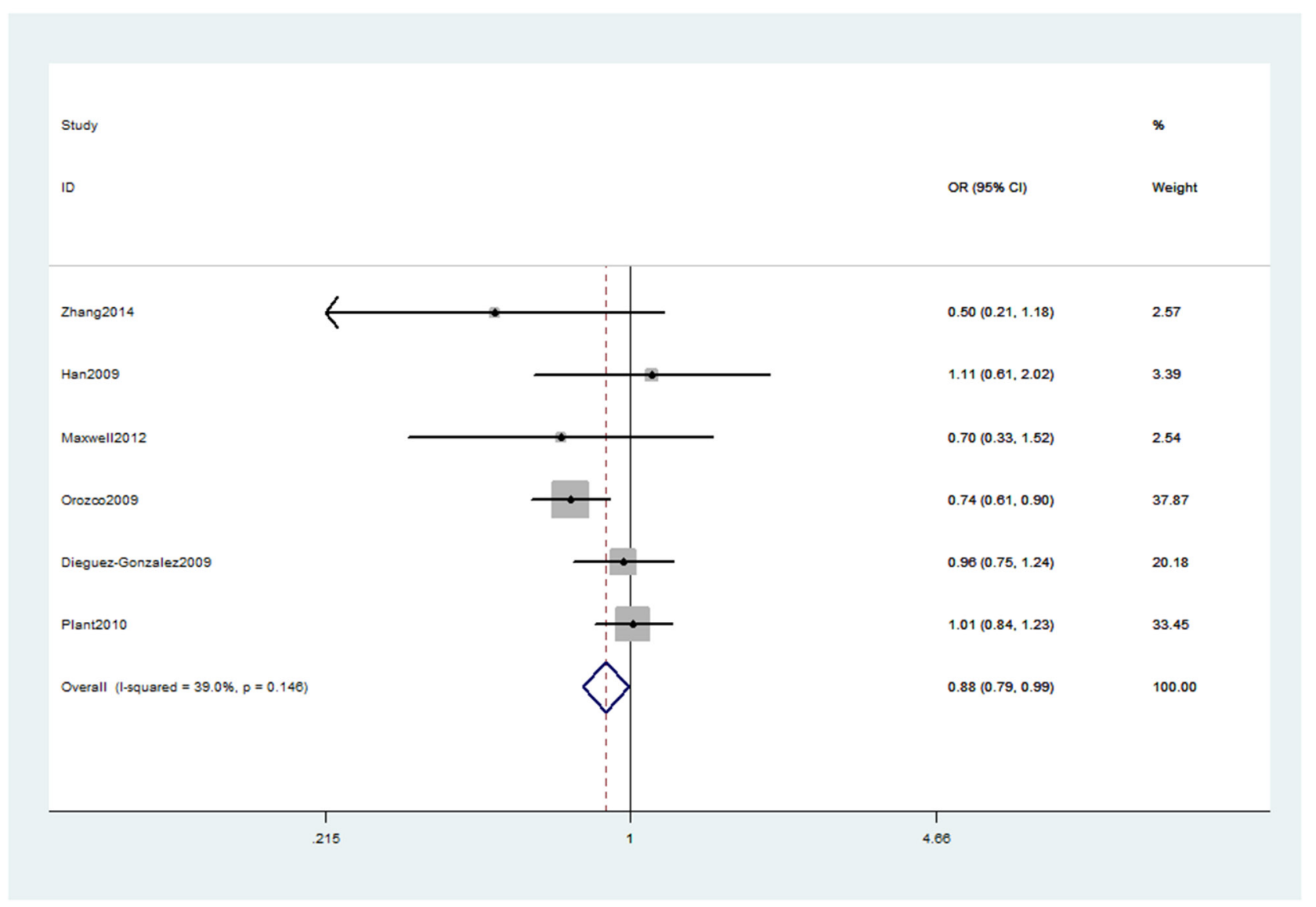

Figure 3: Forest plot shows odds ratio for the associations between rs13207033 polymorphism and RA risk (GA vs. GG). 
Table 3: Summary of the subgroup analyses in this meta-analysis

\begin{tabular}{|c|c|c|c|c|c|}
\hline Comparison & Category & Category & Studies & OR $(95 \%$ CI $)$ & $P$-value \\
\hline \multicolumn{6}{|l|}{ rs10499194 } \\
\hline \multirow[t]{3}{*}{ T vs. C } & Ethnicity & Asian & 3 & $0.86(0.45,1.63)$ & 0.638 \\
\hline & & Caucasian & 9 & $0.86(0.78,0.94)$ & 0.001 \\
\hline & & African-American & 1 & $1.15(0.94,1.41)$ & 0.173 \\
\hline \multirow[t]{3}{*}{$\mathrm{CT}+\mathrm{TT}$ vs. $\mathrm{CC}$} & Ethnicity & Asian & 3 & $0.81(0.40,1.65)$ & 0.561 \\
\hline & & Caucasian & 9 & $0.85(0.76,0.95)$ & 0.005 \\
\hline & & African-American & 1 & $1.17(0.92,1.47)$ & 0.200 \\
\hline \multirow[t]{3}{*}{ TT vs. $\mathrm{CT}+\mathrm{CC}$} & Ethnicity & Asian & 3 & $1.72(0.82,3.62)$ & 0.153 \\
\hline & & Caucasian & 9 & $0.79(0.72,0.86)$ & $<0.001$ \\
\hline & & African-American & 1 & $1.29(0.68,2.46)$ & 0.440 \\
\hline \multirow[t]{3}{*}{ CT vs. CC } & Ethnicity & Asian & 3 & $0.75(0.35,1.61)$ & 0.467 \\
\hline & & Caucasian & 9 & $0.88(0.80,0.98)$ & 0.020 \\
\hline & & African-American & 1 & $1.15(0.90,1.46)$ & 0.262 \\
\hline \multirow[t]{3}{*}{ TT vs. CC } & Ethnicity & Asian & 3 & $1.75(0.83,3.68)$ & 0.141 \\
\hline & & Caucasian & 9 & $0.69(0.58,0.82)$ & $<0.001$ \\
\hline & & African-American & 1 & $1.34(0.70,2.57)$ & 0.374 \\
\hline \multicolumn{6}{|l|}{ rs13207033 } \\
\hline \multirow[t]{2}{*}{ A vs. G } & Ethnicity & Asian & 2 & $1.05(0.92,1.19)$ & 0.451 \\
\hline & & Caucasian & 4 & $0.93(0.85,1.03)$ & 0.170 \\
\hline \multirow[t]{2}{*}{ GA+AA vs. GG } & Ethnicity & Asian & 2 & $1.08(0.94,1.24)$ & 0.296 \\
\hline & & Caucasian & 4 & $0.92(0.82,1.04)$ & 0.174 \\
\hline \multirow[t]{2}{*}{ AA vs. $G A+G G$} & Ethnicity & Asian & 2 & $0.83(0.52,1.34)$ & 0.454 \\
\hline & & Caucasian & 4 & $0.91(0.81,1.02)$ & 0.105 \\
\hline \multirow[t]{2}{*}{ GA vs. GG } & Ethnicity & Asian & 2 & $0.85(0.53,1.37)$ & 0.505 \\
\hline & & Caucasian & 4 & $0.88(0.79,1.00)$ & 0.044 \\
\hline \multirow[t]{2}{*}{ AA vs. GG } & Ethnicity & Asian & 2 & $1.10(0.95,1.27)$ & 0.207 \\
\hline & & Caucasian & 4 & $0.93(0.84,1.03)$ & 0.187 \\
\hline
\end{tabular}

*Bold values are statistically significant $(P<0.05)$

Stratification analyses by ethnicity also found a weak association between rs13207033 polymorphism and Caucasian RA risk.

Several potential limitations should be addressed in this meta-analysis. First, due to limited data, we could not perform further stratification analyses of other potential factors, such as anti-citrullinated peptide antibody (ACPA) and rheumatoid factor (RF). Second, our results were based on unadjusted estimates for confounding factors, which might have affected the final conclusions. Third, we could not assess potential gene-gene and gene-environment interactions because of the lack of relevant data. Fourth, the heterogeneity of this meta-analysis was high in some genetic models. Fifth, the conclusions about rs 10499194 polymorphism among Asians should be interpreted with caution due to limited sample size.

In conclusion, this meta-analysis indicates that TNFAIP3 gene rs10499194, rs13207033 polymorphisms are associated with the decreased risk of RA, especially among Caucasians. Further studies are necessary to validate whether TNFAIP3 gene rs10499194, rs 13207033 polymorphisms contribute to RA susceptibility in other ethnic groups. 


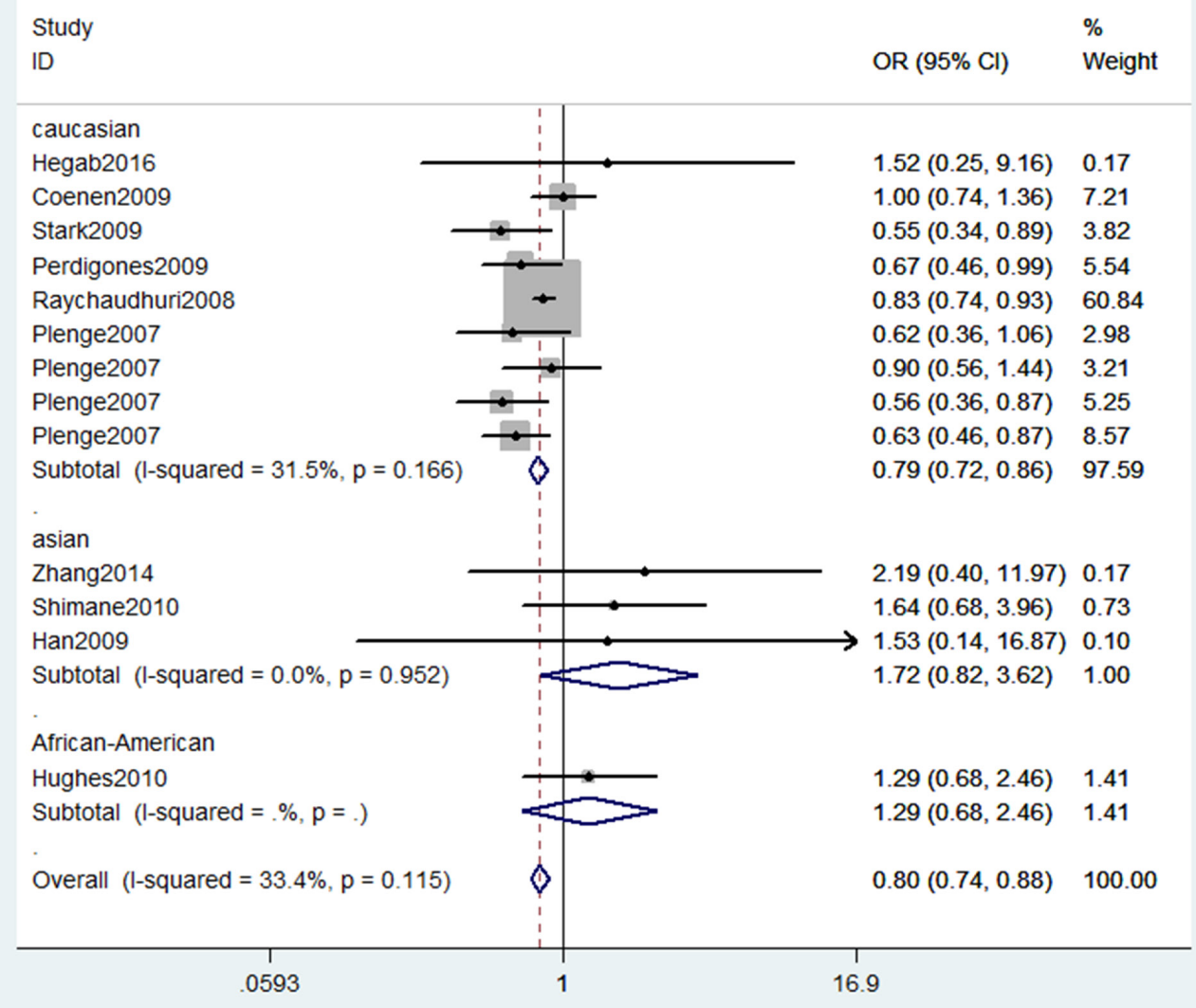

Figure 4: Stratification analyses of ethnicity between rs10499194 polymorphism and RA risk (TT vs. CT+CC).

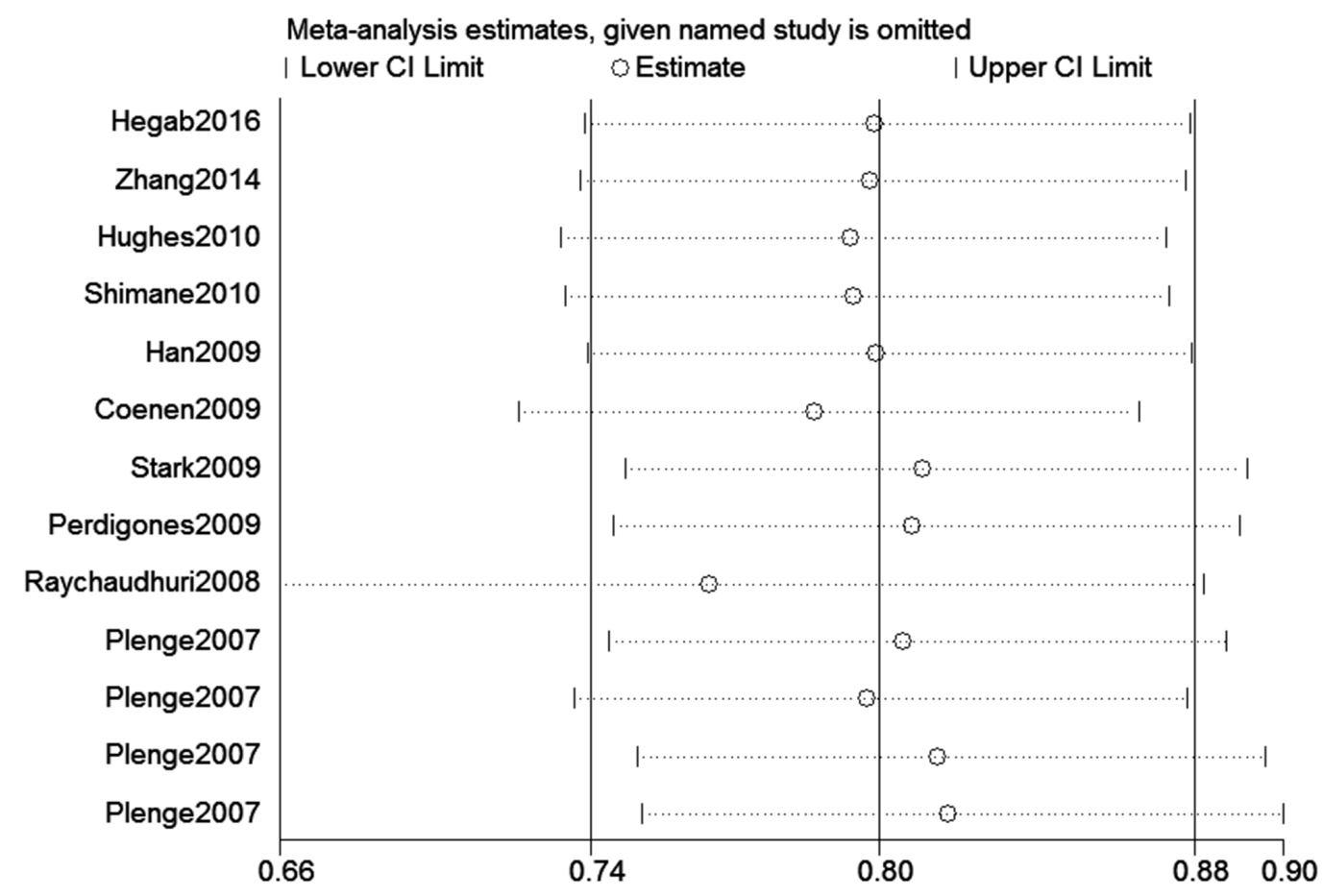

Figure 5: Sensitivity analyses between the rs10499194 polymorphism and RA risk (TT vs. CT+CC). 


\section{Begg's funnel plot with pseudo $95 \%$ confidence limits}

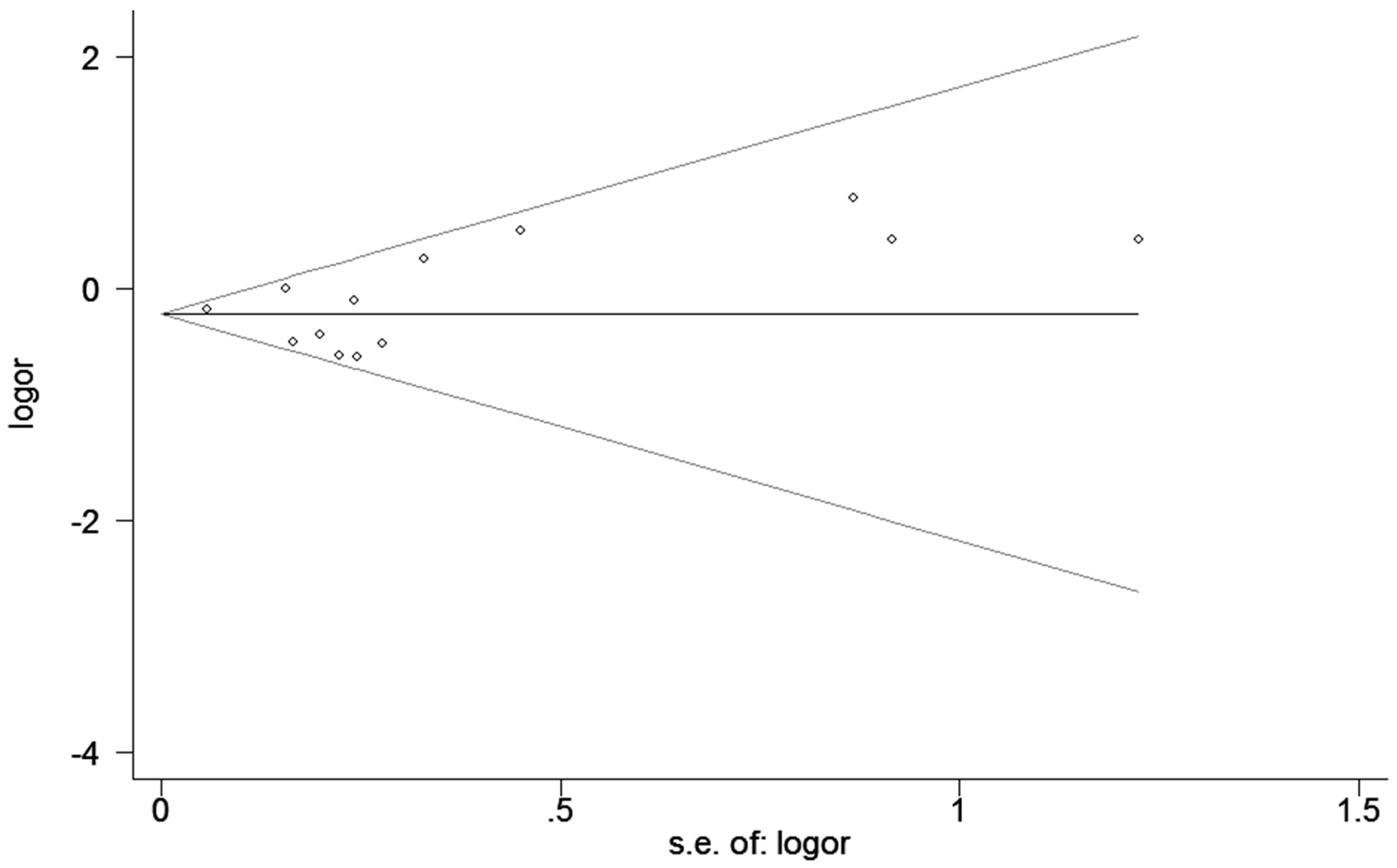

Figure 6: Begg's tests between rs10499194 polymorphism and RA risk (TT vs. CT+CC).

\section{MATERIALS AND METHODS}

\section{Literature search and criteria of inclusion}

We systematically searched the PubMed, Embase, and China Knowledge Resource Integrated Database to identify studies through July 26, 2016. The following search terms were used: "tumor necrosis factor alpha inducible protein 3," "TNFAIP3," "A20," "Rheumatoid Arthritis," "RA," "polymorphism," "SNP" and "polymorphisms". No restrictions were placed on the search. Additional initially omitted studies (such as reference lists of identified studies) have been identified by hand screening. The identified studies conformed to the following criteria: (1) studies that evaluated the association between RA risk and TNFAIP3 gene rs10499194 or rs13207033 polymorphism, (2) studied on human beings, (3) study provided sufficient data to calculate the odds ratios (ORs) and 95\% confidence intervals (CIs), and $P$ value, and (4) case-control study.

\section{Data extraction and quality assessment}

Relevant information was carefully extracted from all eligible studies. The extracted information from all eligible studies including: name of first author, publication year, country of origin, ethnicity, and genotype numbers of cases and controls. Two reviewers independently performed the extraction of data and assessed the study quality based on the NOS [27]. All disagreements were discussed and resolved with consensus.

\section{Statistical analysis}

All statistical analyses were performed using the Stata 11.0 software (StataCorp, College Station, TX, USA). ORs and $95 \%$ CIs were used to assess the strength of associations between TNFAIP3 gene rs10499194, rs13207033 polymorphisms and RA risk. Stratification analysis was carried out by ethnicity. $P<0.05$ was considered statistically significant. When a $\mathrm{Q}$ test indicated $P<0.1$ or $\mathrm{I}^{2}>50 \%$ indicated heterogeneity across studies, a random-effect model was used. Otherwise, the fixed-effects model was applied [28]. Pooled ORs were calculated for allele model, dominant model, recessive model, homozygous model, and heterozygous model. We performed sensitivity analyses by omitting each study in turn to determine the effect on the test of heterogeneity and evaluated the stability of the overall results. We assessed the departure from the HWE in the controls using Pearson's $\chi 2$ test. Potential publication bias was assessed 
by Begger's and Egger's linear regression test [29]; $P<$ 0.05 was considered to indicate statistically significant. The power of this meta-analysis was calculated with a significant value of 0.05 [30].

\section{Abbreviations}

RA, rheumatoid arthritis; TNFAIP3, tumor necrosis factor alpha inducible protein 3; HLA, Human leukocyte antigen; CI, confidence interval; OR, odds ratio; NOS, Newcastle-Ottawa Scale; HWE, Hardy-Weinberg equilibrium; SNP, single nucleotide polymorphism

\section{ACKNOWLEDGMENTS}

This study was supported by National Natural Science Foundation of China, No. 81371927.

\section{CONFLICTS OF INTEREST}

The authors declare no conflict of interest.

\section{REFERENCES}

1. Smolen JS, Aletaha D and McInnes IB. Rheumatoid arthritis. Lancet. 2016.

2. MacGregor AJ, Snieder H, Rigby AS, Koskenvuo M, Kaprio J, Aho K and Silman AJ. Characterizing the quantitative genetic contribution to rheumatoid arthritis using data from twins. Arthritis and rheumatism. 2000; 43:30-37.

3. Kurko J, Besenyei T, Laki J, Glant TT, Mikecz K and Szekanecz Z. Genetics of rheumatoid arthritis - a comprehensive review. Clinical reviews in allergy \& immunology. 2013; 45:170-179.

4. Klareskog L, Catrina AI and Paget S. Rheumatoid arthritis. Lancet. 2009; 373:659-672.

5. Elsby LM, Orozco G, Denton J, Worthington J, Ray DW and Donn RP. Functional evaluation of TNFAIP3 (A20) in rheumatoid arthritis. Clinical and experimental rheumatology. 2010; 28:708-714.

6. Wertz IE, O'Rourke KM, Zhou H, Eby M, Aravind L, Seshagiri S, Wu P, Wiesmann C, Baker R, Boone DL, Ma A, Koonin EV and Dixit VM. De-ubiquitination and ubiquitin ligase domains of A20 downregulate NF-kappaB signalling. Nature. 2004; 430:694-699.

7. Plenge RM, Cotsapas C, Davies L, Price AL, de Bakker PI, Maller J, Pe'er I, Burtt NP, Blumenstiel B, DeFelice M, Parkin M, Barry R, Winslow W, Healy C, Graham RR, Neale BM, et al. Two independent alleles at 6q23 associated with risk of rheumatoid arthritis. Nature genetics. 2007; 39:1477-1482.

8. Thomson W, Barton A, Ke X, Eyre S, Hinks A, Bowes J, Donn R, Symmons D, Hider S, Bruce IN, Wellcome Trust Case Control C, Wilson AG, Marinou I, Morgan A, Emery $\mathrm{P}$, Consortium Y, et al. Rheumatoid arthritis association at 6q23. Nature genetics. 2007; 39:1431-1433.
9. Coenen MJ, Trynka G, Heskamp S, Franke B, van Diemen CC, Smolonska J, van Leeuwen M, Brouwer E, Boezen MH, Postma DS, Platteel M, Zanen P, Lammers JW, Groen HJ, Mali WP, Mulder CJ, et al. Common and different genetic background for rheumatoid arthritis and coeliac disease. Human molecular genetics. 2009; 18:4195-4203.

10. Dieguez-Gonzalez R, Calaza M, Perez-Pampin E, Balsa A, Blanco FJ, Canete JD, Caliz R, Carreno L, de la Serna AR, Fernandez-Gutierrez B, Ortiz AM, Herrero-Beaumont G, Pablos JL, Narvaez J, Navarro F, Marenco JL, et al. Analysis of TNFAIP3, a feedback inhibitor of nuclear factor-kappaB and the neighbor intergenic 6q23 region in rheumatoid arthritis susceptibility. Arthritis research \& therapy. 2009; 11:R42.

11. Han TU, Bang SY, Kang C and Bae SC. TRAF1 polymorphisms associated with rheumatoid arthritis susceptibility in Asians and in Caucasians. Arthritis and rheumatism. 2009; 60:2577-2584.

12. Hegab MM, Abdelwahab AF, El-Sayed Yousef AM, Salem MN, El-Baz W, Abdelrhman S, Elshabacy F, Alhefny A, Abouraya W, Ibrahim SM and Ragab G. CD28 and PTPN22 are associated with susceptibility to rheumatoid arthritis in Egyptians. Human immunology. 2016; 77:522-526.

13. Hughes LB, Reynolds RJ, Brown EE, Kelley JM, Thomson B, Conn DL, Jonas BL, Westfall AO, Padilla MA, Callahan LF, Smith EA, Brasington RD, Edberg JC, Kimberly RP, Moreland LW, Plenge RM, et al. Most common singlenucleotide polymorphisms associated with rheumatoid arthritis in persons of European ancestry confer risk of rheumatoid arthritis in African Americans. Arthritis and rheumatism. 2010; 62:3547-3553.

14. Maxwell JR, Gowers IR, Kuet KP, Barton A, Worthington J and Wilson AG. Expression of the autoimmunity associated TNFAIP3 is increased in rheumatoid arthritis but does not differ according to genotype at 6q23. Rheumatology. 2012; 51:1514-1515.

15. Orozco G, Hinks A, Eyre S, Ke X, Gibbons LJ, Bowes J, Flynn E, Martin P, Wellcome Trust Case Control C, consortium Y, Wilson AG, Bax DE, Morgan AW, Emery P, Steer S, Hocking L, et al. Combined effects of three independent SNPs greatly increase the risk estimate for RA at 6q23. Human molecular genetics. 2009; 18:2693-2699.

16. Perdigones N, Lamas JR, Vigo AG, de la Concha EG, Jover JA, Urcelay E, Gutierrez BF and Martinez A. 6q23 polymorphisms in rheumatoid arthritis Spanish patients. Rheumatology. 2009; 48:618-621.

17. Plant D, Flynn E, Mbarek H, Dieude P, Cornelis F, Arlestig L, Dahlqvist SR, Goulielmos G, Boumpas DT, Sidiropoulos P, Johansen JS, Ornbjerg LM, Hetland ML, Klareskog L, Filer A, Buckley CD, et al. Investigation of potential nonHLA rheumatoid arthritis susceptibility loci in a European cohort increases the evidence for nine markers. Annals of the rheumatic diseases. 2010; 69:1548-1553.

18. Raychaudhuri S, Remmers EF, Lee AT, Hackett R, Guiducci C, Burtt NP, Gianniny L, Korman BD, Padyukov 
L, Kurreeman FA, Chang M, Catanese JJ, Ding B, Wong $\mathrm{S}$, van der Helm-van Mil AH, Neale BM, et al. Common variants at CD40 and other loci confer risk of rheumatoid arthritis. Nature genetics. 2008; 40:1216-1223.

19. Shimane K, Kochi Y, Horita T, Ikari K, Amano H, Hirakata M, Okamoto A, Yamada R, Myouzen K, Suzuki A, Kubo M, Atsumi T, Koike T, Takasaki Y, Momohara S, Yamanaka $\mathrm{H}$, et al. The association of a nonsynonymous singlenucleotide polymorphism in TNFAIP3 with systemic lupus erythematosus and rheumatoid arthritis in the Japanese population. Arthritis and rheumatism. 2010; 62:574-579.

20. Stark K, Rovensky J, Blazickova S, Grosse-Wilde H, Ferencik S, Hengstenberg C and Straub RH. Association of common polymorphisms in known susceptibility genes with rheumatoid arthritis in a Slovak population using osteoarthritis patients as controls. Arthritis research \& therapy. 2009; 11:R70.

21. Zhang X, Li W, Zhang X, Zhao L, Zhang X, Jiang L, Guo Y, Zhang J, Liang Z and Wang X. Single nucleotide polymorphisms in TNFAIP3 were associated with the risks of rheumatoid arthritis in northern Chinese Han population. BMC medical genetics. 2014; 15:56.

22. Lee EG, Boone DL, Chai S, Libby SL, Chien M, Lodolce JP and Ma A. Failure to regulate TNF-induced NF-kappaB and cell death responses in A20-deficient mice. Science. 2000; 289:2350-2354.

23. Vereecke L, Beyaert R and van Loo G. The ubiquitinediting enzyme A20 (TNFAIP3) is a central regulator of immunopathology. Trends in immunology. 2009; 30:383-391.

24. Matmati M, Jacques P, Maelfait J, Verheugen E, Kool M, Sze M, Geboes L, Louagie E, Mc Guire C, Vereecke L, Chu Y, Boon L, Staelens S, Matthys P, Lambrecht BN, SchmidtSupprian M, et al. A20 (TNFAIP3) deficiency in myeloid cells triggers erosive polyarthritis resembling rheumatoid arthritis. Nature genetics. 2011; 43:908-912.

25. Lee YH, Bae SC, Choi SJ, Ji JD and Song GG. Associations between TNFAIP3 gene polymorphisms and rheumatoid arthritis: a meta-analysis. Inflammation research. 2012; 61:635-641.

26. Lemeshow AR, Blum RE, Berlin JA, Stoto MA and Colditz GA. Searching one or two databases was insufficient for meta-analysis of observational studies. Journal of clinical epidemiology. 2005; 58:867-873.

27. Stang A. Critical evaluation of the Newcastle-Ottawa scale for the assessment of the quality of nonrandomized studies in meta-analyses. European journal of epidemiology. 2010; 25:603-605.

28. Higgins JP and Thompson SG. Quantifying heterogeneity in a meta-analysis. Statistics in medicine. 2002; 21:1539-1558.

29. Peters JL, Sutton AJ, Jones DR, Abrams KR and Rushton L. Comparison of two methods to detect publication bias in meta-analysis. Jama. 2006; 295:676-680.

30. Hedges LV and Pigott TD. The power of statistical tests in meta-analysis. Psychological methods. 2001; 6:203-217. 